\title{
Perbedaan metode latihan dan tingkat koordinasi berpengaruh terhadap kemampuan dribbling pemain sepakbola U-12
}

\author{
Ditya Adi Wisesa 1, a *, Siswantoyo Siswantoyo 2, b \\ ${ }^{1}$ Sekolah Sepakbola Real Madrid. Jalan Colombo No. 1, Yogyakarta, 55281 Indonesia. \\ 2 Universitas Negeri Yogyakarta. Jalan Colombo No. 1, Yogyakarta, 55281 Indonesia. \\ a ditya.adi17@gmail.com; b siswantoyo@uny.ac.id \\ * Coressponding Author.
}

Received: 15 January 2021; Revised: 15 February 2021; Accepted: 20 February 2021

\begin{abstract}
Abstrak: Penelitian ini bertujuan untuk mengetahui apakah terdapat (1) perbedaan pengaruh antara metode latihan drill dan metode bermain terhadap kemampuan dribbling, (2) perbedaan pengaruh tingkat kemampuan koordinasi mata-kaki tinggi terhadap kemampuan dribbling, dan (3) interaksi pendekatan drill dan pendekatan bermain serta tingkat kemampuan koordinasi mata-kaki terhadap kemampuan dribbling. Penelitian dilakukan pada pemain sepakbola U-12 menggunakan desain eksperimen faktorial $2 \times 2$. Instrumen pengukuran tingkat kemampuan koordinasi mata-kaki menggunakan Soccer Wall Volley Test dan kemampuan dribbling menggunakan Short Dribbling Test. Hasil penelitian menunjukkan (1) ada perbedaan pengaruh antara metode latihan drill dan metode bermain terhadap peningkatan kemampuan dribbling, metode latihan drill lebih baik dibandingkan pendekatan bermain; (2) Ada perbedaan pengaruh antara tingkat kemampuan koordinasi mata-kaki terhadap kemampuan dribbling, pemain dengan koordinasi mata-kaki tinggi lebih baik dibandingkan koordinasi mata-kaki rendah; dan (3) Ada interaksi antara pendekatan drill dan pendekatan bermain serta tingkat koordinasi mata-kaki terhadap kemampuan dribbling.
\end{abstract}

Kata Kunci: koordinasi mata-kaki, keterampilan dribbling, metode latihan, sepakbola

\section{The influence of the differences between the training method and the coordination level on the dribbling skills of the u-12 football players}

Abstract: This study aims to investigate (1) the effect of the drill training method and the playing method on dribbling ability, (2) the effect of the level of eye-foot coordination ability on dribbling ability, and (3) the interaction between the drill approach and the playing approach and the level of coordination eyefoot ability to dribbling skills. The study was conducted on U-12 soccer players using a 2 × 2 factorial experimental design. The instrument used to measure eye-foot coordination skills is the Soccer Wall Volley Test, while dribbling abilities measured with the Short Dribbling Test. The results showed (1) there was a difference in the effect of the drill training method and the playing method on increasing dribbling skills; the drill training method was better than the playing approach; (2) There is a difference in the effect of the level of eye-foot coordination on dribbling ability, players with high eye-foot coordination are better than low eye-foot coordination; and (3) There is an interaction between the drill approach and the playing approach as well as the eye-foot coordination level on dribbling skills..

Keywords: dribbling skills, eye-foot coordination, football, training methods.

How to Cite: Wisesa, D., \& Siswantoyo, S. (2021). Perbedaan metode latihan dan tingkat koordinasi berpengaruh terhadap kemampuan dribbling pemain sepakbola U-12. Sepakbola, 1(1), 32-38. doi:http://dx.doi.org/10.33292/sepakbola.v1i1.91

\section{PENDAHULUAN}

Seorang pemain sepakbola yang baik harus menguasai teknik dasar bermain, salah satunya adalah dribbling (menggiring) bola. Karakteristik aksi dribbling adalah menggerakan bola dari satu titik ke titik lain di lapangan dengan menggunakan kaki (Koger, 2007). Menggiring bola sangat penting dikuasai, sebab jika seorang pemain dapat melakukan menggiring bola secara 
efektif dapat memberikan keuntungan yang sangat besar dalam sebuah tim. Penelitian terdahulu yang berkaitan dengan cara meningkatkan kecepatan dan kekuatan dribbling melalui latihan kelincahan dan kelentukan telah dilakukan oleh Utama et al. (2015). Kemampuan dribbling sepakbola membutuhkan dukungan kemampuan kondisi fisik dan koordinasi gerak yang baik.

Berdasarkan observasi di lapangan, peneliti melihat pada umumnya para siswa SSB Real Madrid UNY kelahiran 10 - 12 tahun kurang memahami bagaimana melakukan teknik dribbling sepakbola yang benar. Pemain sepakbola U-12 masih dalam tahap belajar sehingga latihan dinilai dapat berpengaruh pada hasil belajar. Gerak yang terjadi dalam aktivitas olahraga merupakan akibat adanya stimulus yang diproses di dalam otak dan selanjutnya direspons melalui kontraksi otot, setelah merima perintah dari sistem komando syaraf yaitu otak. Hasil belajar adalah perubahan tingkah laku yang meliputi kemampuan kognitif, afektif, dan psikomotor dalam situasi tertentu berkat pengalamannya berulang-ulang (Waliana et al., 2014).

Metode meningkatkan kemampuan dribbling dalam permainan sepakbola bervariasi. Metode drill, metode bermain, metode small sided game adalah beberapa diantaranya. Metode drill dribbling dilakukan dengan cara berulang-ulang dengan memperhatikan program latihan yang sudah ditentukan. Metode ini dinilai dapat meningkatkan teknik dasar dribbling siswa sekolah sepakbola sebagaimana hasil penelitian Aprianova dan Hariadi (2016). Penelitian lain menunjukkan pendekatan bermain dapat meningkatkan kemampuan dribbling sepakbola (E. Y. Pratama et al., 2018). Kesimpulan pada penelitian lain adalah bahwa pembelajaran teknik dasar dribbling pada pembelajaran sepakbola dengan modifikasi permainan dapat meningkatkan gerak dasar siswa kelas V (Taufik, 2018).

Perbedaan metode dalam melatih kemampuan dribbling dan tingkat kemampuan koordinasi pemain diasumsikan menghasilkan peningkatan kemampuan dribbling yang berbeda. Koordinasi mata-kaki merupakan salah satu faktor yang dapat mempengaruhi kemampuan dribbling sepakbola. Koordinasi mata-kaki berperan terhadap gerakan dribbling pada saat seorang pemain bola harus memperhatikan bola dan situasi permainan Berdasarkan hal tersebut, penelitian ini bertujuan untuk mengetahui: (1) Adakah pengaruh pendekatan drill terhadap kemampuan dribbling pemain sepakbola U-12? (2) Adakah pengaruh pendekatan bermain terhadap kemampuan dribbling pemain sepakbola U-12? (3) Adakah perbedaan pengaruh antara koordinasi mata-kaki tinggi dan koordinasi mata-kaki rendah terhadap kemampuan dribbling pemain sepakbola U-12? Dan (4) Adakah interaksi antara pendekatan latihan dan koordinasi mata-kaki terhadap kemampuan dribbling pemain sepakbola U-12?

\section{METODE}

Penelitian ini menggunakan metode eksperimen dengan desain penelitian berupa faktorial 2x2. Semua taraf faktor disilangkan dengan semua taraf tiap faktor lainnya yang ada dalam eksperimen. Rancangan desain dapat dilihat pada Tabel 1.

Tabel 1. Rancangan Desain Faktorial

\begin{tabular}{lcc}
\hline \multirow{2}{*}{ Koordinasi Mata kaki (B) } & \multicolumn{2}{c}{ Metode Latihan (A) } \\
\cline { 2 - 3 } & Drill (A1) & Bermain (A2) \\
\hline Tinggi (B1) & A1. B1 & A2. B1 \\
Rendah (B2) & A1. B2 & A2. B2 \\
\hline
\end{tabular}

Keterangan:

A1B1: Kelompok latihan pendekatan drill dengan koordinasi mata-kaki tinggi

A2B1: Kelompok latihan pendekatan bermain dengan koordinasi mata-kaki tinggi

A1B2: Kelompok latihan pendekatan drill dengan koordinasi mata-kaki rendah

A2B2: Kelompok latihan pendekatan bermain dengan koordinasi mata kaki rendah

Populasi dalam penelitian ini adalah pemain di SSB Real Madrid UNY yang berjumlah 38 pemain dengan karakteristik: berusia 10-12 tahun, kehadiran miminal 75\%, dan telah berlatih minimal 3 bulan. Sampel diambil menggunakan teknik random sampling dengan cara membagi kelompok berdasarkan hasil peringkat tes koordinasi. Berdasarkan rangking, ditentukan 27\% kelompok atas dan 27\% kelompok bawah. Dengan demikian, pengelompokan sampel diambil dari pemain yang memiliki koordinasi mata-kaki tinggi sebanyak $27 \%$ (10 pemain) dan pemain yang 
memiliki koordinasi mata-kaki rendah sebanyak 27\% (10 pemain). Kemudian dari data tersebut dibagi menjadi dua kelompok dengan cara diacak (random) dan didapatkan masing-masing 5 pemain yang memiliki koordinasi mata-kaki tinggi diberi perlakuan dengan metode latihan drill dan bermain, hal yang sama juga dilakukan untuk kelompok pemain yang memiliki koordinasi mata-kaki rendah.

Variabel dalam penelitian ini terdiri dari dua variabel bebas (independent) manipulative, yaitu pendekatan drill dan pendekatan bermain. Sementara variabel bebas atributif, yaitu koordinasi mata-kaki. Variabel terikatnya (dependent) adalah kemampuan dribbling sepak bola. Sesuai dengan variabel yang diteliti, data yang harus dikumpulkan adalah tes koordinasi matakaki dan tes kemampuan dribbling. Teknik pengumpulan data menggunakan tes. Instrumen koordinasi mata-kaki menggunakan tes Soccer Wall Volley Test dengan validitas sebesar 0,915 dan reliabilitas sebesar 0,789. Sedangkan kemampuan dribbling dari tes "Short Dribbling Test" dengan validitas sebesar 0,926 dan reliabilitas sebesar 0,796.

Teknik analisis yang digunakan anava dua jalur (two ways ANOVA) pada taraf signifikansi $\alpha=0,05$. Sebelum teknik analisis varians digunakan, terlebih dahulu dilakukan uji prasyarat analisis yang meliputi uji normalitas dan uji homogenitas. Uji normalitas menggunakan uji Kolmogorof-Smirnov. Uji homogenitas varians menggunakan uji Levene's test. Untuk menguji hipotesis dilakukan dengan menggunakan ANOVA dua jalur (ANOVA two-way) dan apabila terbukti terdapat interaksi maka dilakukan uji lanjutan yaitu uji Tukey, dengan menggunakan program software SPSS version 20.0 for windows dengan taraf signifikansi 5\% atau 0,05.

\section{HASIL DAN PEMBAHASAN}

Uji normalitas data dalam penelitian ini digunakan metode Kolmogorov Smirnov. Hasil uji normalitas disajikan pada Tabel 2.

Tabel 3. Uji Normalitas

\begin{tabular}{ccc}
\hline Data & $p$ & Keterangan \\
\hline Pretest A1B1 & 0,636 & Normal \\
Posttest A1B1 & 0,787 & Normal \\
Pretest A2B1 & 0,956 & Normal \\
Posttest A2B1 & 0,960 & Normal \\
Pretest A1B2 & 0,877 & Normal \\
Posttest A1B2 & 0,942 & Normal \\
Pretest A2B2 & 0,734 & Normal \\
Posttest A2B2 & 0,699 & Normal \\
\hline
\end{tabular}

Berdasarkan analisis statistik uji normalitas pretest dan posttest kemampuan dribbling dan kinerja dribbling didapat dari hasil uji normalitas data nilai signifikansi $p>0,05$, yang berarti data berdistribusi normal. Uji homogenitas pada penelitian ini adalah uji Levene Test. Hasil uji homogenitas disajikan pada Tabel 3.

Tabel 4. Uji Homogenitas

\begin{tabular}{ccc}
\hline Kelompok & Sig. & Keterangan \\
\hline Pretest & 0,501 & Homogen \\
Posttest & 0,402 & Homogen \\
\hline
\end{tabular}

Berdasarkan Tabel 3, pretest diperoleh nilai signifikansi sebesar 0,501 $\geq 0,05$ dan pada posttest didapat nilai signifikansi sebesar $0,402 \geq 0,05$. Hal berarti dalam kelompok data memiliki varian yang homogen. Pengujian hipotesis penelitian dilakukan berdasarkan hasil analisis data dan interpretasi analisis ANOVA dua jalur (ANOVA two-way). Hasil Uji Hipotesis disajikan Tabel 4.

Tabel 4. Uji Anova

\begin{tabular}{lccc}
\hline Source & Type III Sum of Squares & F & Sig. \\
\hline Metode Latihan & 4,831 & 22,934 & .000 \\
Koordinasi & 5,778 & 27,428 & .000 \\
Metode Latihan * Koordinasi & 3,128 & 14,850 & .001 \\
\hline
\end{tabular}


Hipotesis pertama: "Ada perbedaan pengaruh yang signifikan antara metode latihan drill dan metode bermain terhadap kemampuan dribbling." Dari tabel di atas dapat dilihat bahwa nilai signifikansi $p$ sebesar 0,000. Karena nilai signifikansi p sebesar 0,000 $<0,05$, berarti Ho ditolak. Dengan demikian, terdapat perbedaan pengaruh yang signifikan antara metode latihan pendekatan drill dan metode bermain terhadap kemampuan dribbling. Metode latihan drill lebih tinggi (baik) dengan nilai rata-rata posttest sebesar 10,8040 dibandingkan metode latihan bermain dengan nilai rata-rata posttest sebesar 12,5780. Hipotesis pertama telah terbukti.

Hipotesis kedua: "Ada perbedaan pengaruh antara koordinasi mata-kaki tinggi dan koordinasi mata-kaki rendah terhadap kemampuan dribbling." Hasil uji ANOVA pada Tabel 4 menunjukkan nilai signifikansi $p$ sebesar 0,000. Karena nilai signifikansi p sebesar 0,000 $<0,05$, berarti Ho ditolak. Berdasarkan hasil analisis, pemain yang memiliki koordinasi mata-kaki tinggi lebih tinggi (baik) dengan nilai rata-rata posttest sebesar 11,69 detik dibandingkan dengan pemain yang memiliki koordinasi mata-kaki rendah dengan nilai rata-rata posttest sebesar 12,77 detik. Dengan demikian, hipotesis kedua telah terbukti.

Hipotesis ketiga: "Ada interaksi antara pendekatan drill dan pendekatan bermain dan koordinasi mata-kaki terhadap kemampuan dribbling." Hasil uji ANOVA pada Tabel 4 menunjukkan nilai signifikansi p sebesar 0,001. Karena nilai signifikansi p sebesar 0,001<0,05, berarti Ho ditolak. Terdapat interaksi yang signifikan antara pendekatan (drill dan bermain) dan koordinasi mata-kaki (tinggi dan rendah) terhadap kemampuan dribbling. Berdasarkan hasil ini, perlu dilakukan uji lanjut dengan menggunakan uji Tukey (Tabel 5).

Tabel 5. Hasil Uji Poshoc

\begin{tabular}{crrr}
\hline Kelompok & Interaksi & Std. Error & \multicolumn{1}{c}{ Sig. } \\
\hline A1B1 & $-1,8660^{*}$ &, 29029 &, 000 \\
& $-1,7740^{*}$ &, 29029 &, 000 \\
& $-2,0580^{*}$ &, 29029 &, 000 \\
A2B1 & $1,8660^{*}$ &, 29029 &, 000 \\
&, 0920 &, 29029 &, 989 \\
&,- 1920 &, 29029 &, 910 \\
A1B2 & $1,7740^{*}$ &, 29029 &, 000 \\
&,- 0920 &, 29029 &, 989 \\
&,- 2840 &, 29029 &, 763 \\
A2B2 & $2,0580^{*}$ &, 29029 &, 000 \\
&, 1920 &, 29029 &, 910 \\
&, 2840 &, 29029 &, 763 \\
\hline
\end{tabular}

Berdasarkan Tabel 5 hasil perhitungan uji Tukey pada tanda asterisk (*) menunjukkan bahwa pasangan-pasangan yang memiliki interaksi atau pasangan yang berbeda secara nyata (signifikan) adalah: (1) A1B1-A1B2, (2) A1B1-A2B1, (3) A1B1-A2B2, (4) A1B2-A1B1, (5) A2B1A1B1, dan (6) A2B2-A1B1.

\section{Perbedaan Pengaruh antara Pendekatan Drill dan Pendekatan Bermain terhadap Kemampuan Dribbling}

Berdasarkan pengujian hipotesis pertama diketahui bahwa pendekatan drill lebih tinggi (baik) dibandingkan dengan pendekatan bermain terhadap kemampuan dribbling. Keefektifan dan kemampuan mengantisipasi gerak dapat ditingkatkan dengan cara melakukan latihan-latihan drill secara kontinyu. Pelatih menjelaskan bagian-bagian kaki yang digunakan dalam melakukan drible. Pelatih selanjutnya mendemontrasikan teknik dribbling sepakbola dengan baik dan benar. Setelah itu, pelatih menyusun organisasi latihan agar pemain dapat melakukan tugas ajar dengan baik dan semua pemain mendapat kesempatan yang sama. Pelatih dapat menyusun tata urutan gerakan dribbling sepakbola sesuai dengan kondisi yang ada. Sebagai contoh, dribbling sepakbola lurus secara bergantian dan bentuk latihan menggiring bola lainnya. Hasil ini sejalan dengan temuan pada penelitian tindakan olahraga yang dilakukan oleh Aprianova dan Hariadi (2016) pada pemain sekolah sepakbola U-15.

Pada peningkatan teknik dasar sepakbola lainnya, metode drill yang diberikan selama 12 pertemuan dalam 2 siklus dapat meningkatkan teknik shooting sepakbola menggunakan pung- 
gung kaki (Istofian \& Amiq, 2016). Namun perbedaan antara pembelajaran dengan metode drill dan metode bermain terhadap hasil belajar passing sepakbola peserta ekstrakurikuler sepakbola usia 16-17 tahun tidak signifikan (Syarifudin et al., 2017). Metode drill banyak digunakan sebagai pendekatan latihan untuk meningkatkan keterampilan dasar sepakbola selain dribbling.

Meningkatnya hasil belajar dribbling pada kelompok metode drill dapat dilihat pada faktor pengulangan. Pemain belajar melakukan suatu teknik gerak dasar dengan cara mengulang gerakan secara terus menerus sehingga membuat pemain terbiasa. Dengan demikian, secara tidak langsung, respon pemain ketika melakukan dribbling akan berubah menjadi lebih baik dari sebelumnya dan meminimalisir kesalahan dengan adanya gerakan pengulangan saat pembelajaran (Maskrisnadi et al., 2019). Selanjutnya gerak yang dilakukan secara berulang-ulang akan tersimpan dalam memori pelaku yang sewaktu-waktu akan muncul bila ada stimulus yang sama. Untuk itu, keterampilan gerak dalam olahraga harus selalu dilatihkan secara berulang-ulang agar tidak mudah hilang dari memori, sehingga individu tetap terampil dalam setiap melakukan gerakan.

\section{Perbedaan Pengaruh antara Koordinasi Mata-Kaki Tinggi dan Mata-Kaki Rendah terhadap Kemampuan Dribbling}

Koordinasi mata-kaki adalah satu integrasi antara mata sebagai pemegang fungsi utama dalam hal ini melihat bola dan situasi permainan yang dihadapi saat menendang bola dan kaki sebagai pemegang fungsi yang melakukan suatu gerakan, yaitu menyentuh atau menendang bola agar dapat bergerak dari tempat semula. Kemampuan dribbling yang baik dipengaruhi koordinasi mata-kaki yang dimiliki. Integrasi yang melibatkan dua bagian gerak yaitu mata dan kaki harus dirangkaikan menjadi satu pola gerakan yang baik dan harmonis untuk mendukung kemampuan dribbling. Dalam permainan sepakbola sangat dibutuhkan koordinasi mata-kaki yang baik (Tiu et al., 2012).

Hasil analisis menunjukkan bahwa pemain dengan kemampuan koordinasi mata-kaki tinggi lebih baik dibandingkan pemain dengan kemampuan koordinasi mata-kaki rendah terhadap kemampuan dribbling. Hasil ini sejalan dengan temuan Hartanto (2015) yang menunjukkan kemampuan dribbling pada pemain dengan koordinasi mata-kaki tinggi lebih baik daripada pemain dengan koordinasi mata-kaki rendah. Studi tersebut juga menginformasikan bahwa peningkatan pembelajaran latihan menggiring bola menggunakan bola standar lebih baik dibandingkan dengan pembelajaran latihan menggiring bola menggunakan bola tidak standar.

Dribbling sepakbola merupakan salah satu bentuk ketrampilan sepakbola yang menuntut kualitas koordinasi mata dan kaki. Studi lain yang menunjukkan kemampuan kelincahan serta koordinasi mata-kaki berkontribusi terhadap peningkatan keterampilan dribbling dalam permainan sepak bola adalah penelitian Mubarok (2018). Pada pemain sekolah sepakbola hasil yang sama juga ditemui pada penelitian Ilmi dan Kiram (2019). Dalam melakukan keterampilan dribbling setiap pemain membutuhkan kemampuan kelincahan serta koordinasi mata-kaki yang sangat baik. Sementara itu dalam hasil penelitian Pratama et al. (2018), koordinasi mata-kaki memberikan sumbangan efektif sebesar 29,5 \% terhadap kemampuan menggiring bola. Nilai ini lebih besar dibandingkan variabel lain, yaitu kelincahan, keseimbangan dinamis dan fleksibilitas togok.

Interaksi Pendekatan Drill dan Bermain dan Koordinasi Mata-Kaki terhadap Kemampuan Dribbling

Hasil penelitian ini menunjukkan terdapat interaksi yang signifikan antara pendekatan drill dan pendekatan bermain dan koordinasi mata-kaki terhadap kemampuan dribbling sepakbola pada siswa SSB Real Madrid UNY. Dari tabel yang disajikan, bentuk interaksi tampak bahwa faktorfaktor utama penelitian dalam bentuk dua faktor menunjukkan interaksi yang signifikan. Dalam hasil penelitian ini interaksi yang memiliki arti bahwa setiap sel atau kelompok terdapat perbedaan pengaruh setiap kelompok yang dipasang-pasangkan.

Pendekatan drill dan bermain merupakan bentuk latihan dribbling sepakbola yang pelaksanaanya berbeda. Latihan dribbling sepakbola dengan pendekatan drill merupakan bentuk latihan yang pelaksanaanya dilakukan secara berulang-ulang dan beban latihan ditingkatkan secara bertahap. Sedangkan latihan dribbling sepakbola dengan pendekatan bermain merupakan latihan 
dribbling sepakbola yang dikemas dalam bentuk permainan. Pendekatan drill dan bermain masing-masing menuntut siswa melakukan gerakan dribbling sepakbola. Adapun salah satu kelemahan dari pendekatan bermain adalah kurangnya sentuhan bola yang dilakukan serta kelemahan metode drill ialah pemain merasa bosan dan jenuh dengan model latihan yang dilatihkan (Prayadi \& Rachman, 2013)

Dalam gerakan dribbling dibutuhkan koordinasi mata-kaki yang baik. Latihan dribbling sepakbola dengan metode drill dan bermain masing-masing dilakukan secara berulang-ulang sehingga akan meningkatkan koordinasi mata-kaki. Dengan meningkatnya koordinasi mata-kaki akan sangat mendukung gerakan dribbling sepakbola. Ditinjau dari pelaksanaan latihan dribbling sepakbola dengan metode drill dan bermain menunjukkan bahwa siswa yang memiliki koordinasi mata-kaki tinggi cocok untuk latihan dribbling dengan metode drill. Hal ini karena dalam metode drill gerakannya sangat kompleks sehingga dibutuhkan koordinasi mata-kaki yang tinggi. Sedangkan siswa yang memiliki koordinasi mata-kaki rendah cocok untuk latihan dribbling dengan metode bermain karena bentuk latihan yang sederhana. Hal ini karena latihan dribbling sepakbola dengan metode bermain bentuk latihannya sangat sederhana, sehingga siswa yang memiliki koordinasi mata-kaki rendah akan mampu melakukannya dengan baik.

\section{SIMPULAN}

Berdasarkan hasil analisis data yang telah dilakukan, diperoleh kesimpulan sebagai berikut: (1) Pendekatan drill lebih tinggi (baik) dibandingkan dengan pendekatan bermain. (2) Pemain dengan kemampuan koordinasi mata kaki tinggi lebih tinggi (baik) dibandingkan dengan pemain dengan kemampuan koordinasi mata kaki rendah. (3) Ada interaksi pendekatan drill dan bermain dan koordinasi mata-kaki terhadap kemampuan dribbling sepakbola pemain sepakbola U-12 di SSB Real Madrid UNY. Pendekatan drill lebih efektif digunakan daripada pendekatan bermain, untuk itu disarankan kepada pelatih untuk menggunakan pendekatan drill dalam meningkatkan kemampuan dribbling dengan memperhatikan kelemahan metode drill, yaitu kebosanan pemain.

\section{DAFTAR PUSTAKA}

Aprianova, F., \& Hariadi, I. (2016). Metode drill untuk meningkatkan teknik dasar menggiring bola (dribbling) dalam permainan sepakbola pada siswa Sekolah Sepakbola Putra Zodiac Kabupaten Bojonegoro usia 13-15 tahun. Jurnal Kepelatihan Olahraga, 1(1), 63-74.

Hartanto, D. (2015). Pengaruh latihan menggiring bola menggunakan bola berbeda ditinjau dari koordinasi mata-kaki terhadap peningkatan kemampuan menggiring bola. Jurnal Pendidikan Olahraga, 4(1), 56-65.

Ilmi, M., \& Kiram, Y. (2019). Hubungan koordinasi mata-kaki dan kelincahan dengan kemampuan dribbling pemain sepakbola di Sekolah Sepakbola (ssb) Excellent Kota Batusangkar. Jurnal Patriot, 1(1), 204-212.

Istofian, R. S., \& Amiq, F. (2016). Metode drill untuk meningkatkan teknik menendang bola (shooting) dalam permainan sepakbola usia 13-14 tahun. Jurnal Kepelatihan Olahraga, 1(1), 105-113.

Koger, R. (2007). Latihan dasar andal sepak bola remaja. Macanan Jaya Cemerlang.

Maskrisnadi, G., Hariyoko, H., \& Wahyudi, U. (2019). Pengaruh metode pembelajaran drill dan small sided games terhadap hasil belajar keterampilan dribbling sepakbola pada siswa ekstrakurikuler. Indonesia Journal of Sports and Physical Education, 1(1), 6-11.

Mubarok, M. Z. (2018). Kontribusi kelincahan dengan koordinasi mata-kaki terhadap keterampilan dribbling dalam permainan sepakbola. Jurnal Kependidikan Jasmani Dan Olahraga, 2(1), 37-45.

Pratama, A. P., Sugiyanto, S., \& Kristiyanto, A. (2018). Sumbangan koordinasi mata-kaki, kelincahan, keseimbangan dinamis dan fleksibilitas togok terhadap kemampuan menggiring bola pada permainan sepak bola. Jurnal SPORTIF : Jurnal Penelitian Pembelajaran, 4(1), 15-27. 
Pratama, E. Y., Alnedral, A., \& Fardi, A. (2018). Meningkatkan kemampuan dribbling sepakbola dengan pendekatan bermain. Cerdas Sifa, 1(2), 42-53.

Prayadi, H. Y., \& Rachman, H. A. (2013). Pengaruh metode latihan dan power lengan terhadap kemampuan smash bulutangkis. Jurnal Keolahragaan, 1(1), 63-71.

Syarifudin, M. F., Hariyoko, H., \& Wahyudi, U. (2017). Pengaruh metode drill dan metode bermain terhadap hasil belajar passing sepakbola pada peserta ekstrakurikuler sepakbola usia 16-17 tahun. Gelanggang Pendidikan Jasmani Indonesia, 1(2), 271-281. https://doi.org/10.17977/um040v1i2p271-281

Taufik, M. S. (2018). Meningkatkan teknik dasar dribbling sepakbola melalui modifikasi permainan. Maenpo, 8(1), 26. https://doi.org/10.35194/jm.v8i1.914

Tiu, W., Salipot, C. L., Maquiraya, C. A., Burkley, D. M., Castaneda, M., \& Gomez, M. G. (2012). Effects of a modified football program in improving foot-eye coordination among students with intellectual disability. Educational Research, 3(4), 412-423.

Utama, A. Z., Hariyanto, E., \& Sudjana, I. N. (2015). Pengaruh latihan kelincahan dan kelentukan terhadap keterampilan dribbling sepakbola SSB PAS-ITN Kabupaten Malang. Jurnal Pendidikan Jasmani, 25(1), 31-38. https://doi.org/10.17977/pj.v25i1.4887.g1286

Waliana, I. P., Adi, I. P. P., \& Darmayasa, I. P. (2014). Kooperatif tipe STAD untuk meningkatkan aktivitas dan hasil belajar dribbling sepak bola. Jurusan Pendidikan Jasmani Kesehatan Dan Rekreasi, 2(1), 1-11. 